\title{
Social Integration in Public Spaces \& Landscapes: Perceptions and Experiences towards Multicultural Shanghai
}

\author{
Liu Binyi, Floyd M. Mwanza* \\ Department of Landscape Studies, Tongji University, Shanghai, China \\ Email: "loydmwanza@gmail.com
}

Received January $14^{\text {th }}$, 2014; revised February $15^{\text {th }}, 2014$; accepted February $22^{\text {nd }}, 2014$

\begin{abstract}
Copyright (C) 2014 Liu Binyi, Floyd M. Mwanza. This is an open access article distributed under the Creative Commons Attribution License, which permits unrestricted use, distribution, and reproduction in any medium, provided the original work is properly cited. In accordance of the Creative Commons Attribution License all Copyrights (C) 2014 are reserved for SCIRP and the owner of the intellectual property Liu Binyi, Floyd M. Mwanza. All Copyright (C) 2014 are guarded by law and by SCIRP as a guardian.
\end{abstract}

\begin{abstract}
Multiculturalism in today's globalised economies has become a hot topic. This research seeks to document the differing experiences of non-Chinese and Chinese to public spaces and landscapes, focusing on the factors influencing the involvement of non-Chinese people in public spaces and landscapes. The study seeks to ascertain whether particular public spaces have social significance in the integration of non-Chinese people in Shanghai, China, and whether there is a need to develop a policy in relation to strategies for social integration in the now thriving multicultural Shanghai communities. Multiculturalism and Urbanism for future cities can be the basis on which a problem statement(s) can be developed for further research. Multicultural social integration is about recognising diversity and indifferences. People from different cultural backgrounds may value the public space landscape quite differently to natives. Social integration allows cultural richness to open hearts and minds to different ways of seeing and experiencing public parks and landscapes. It can tell us something about the ways in which people adapt their traditions to different circumstances in a new country. It is the hope of this research that a series of studies on "Multiculturalism and Social Integration and Landscape in Asian Cities" will be done.
\end{abstract}

Keywords: Immigrants; Integration; Landscape; Multicultural; Social

\section{Introduction}

Multicultural integration is about recognising diversity and difference, people from different cultural backgrounds who may value the landscape quite differently. Novica (2001) draws the stories and traditions of different cultural groups as part of the heritage. This cultural richness can open our hearts and minds to different ways of seeing and experiencing public space and landscape. It can tell us something about the ways in which people adapt their traditions to different circumstances in a new country. These debates originate from the fact that in recent decades, societies have become multicultural. As shown in Figure 1 since the Industrial Revolution Immigration (1880-1920) set records that stood until 2000. A number of developments led to various ethnic groups migrating to other countries (Merrifield \& Swyngedouw, 1996). In Britain, proposed improvement in a lot of minority ethnic people, and discussions of what nationhood and belonging mean in multiethnic society, are well documented in the Parekh ReportRunnymede Trust (2000: p. 23) and Macpherson (1999). This has seen new issues enter the international debate, from researchers, city and urban planners/designers and policy makers alike. As Amin (2002) stated, almost no day goes by without discussion of some of these issues in the media by politicians, journalists, experts and stakeholders, all surrounded by a mountain of new research and existing knowledge. Much as the

\footnotetext{
*Corresponding author.
}

issues are varied and complex, the notable pace and volume of mixed society China is becoming, it has given rise to opinions on how a multicultural Shanghai policy(ies) can be formulated. This has given rise to scope for radically new insights every day and the public arena continues to crave for new discoveries on multi cultural issues. This is the scope of this modest contribution within a field of excellent existing scholarship on "multicultural landscapes" race and ethnicity in Shanghai, China.

This background of intense societal debates, dominated by a discourse of integration that focuses on cultural values encourages this paper. This study seeks to set a prime site for reconciling and overcoming ethnic cultural differences. It also aligns itself with a perspective that takes ethnicity as a mobile and incomplete process, seeking, firstly, to expose current popular stereotyping - the very real cultural dynamism that is to be found within minority ethnic (and local Chinese) communities, and secondly, to interpret questions of inter-ethnic understanding and exchange as a matter of public participation fragile and temporary resolutions springing from the vibrant clash between empowered publics - rather than as a matter of policy fixes or cross-ethnic community cohesion. The study focuses on the problem of inter-ethnic intolerance.

\section{Research Objectives and Questions}

This study focuses on the problem of inter-ethnic intolerance 


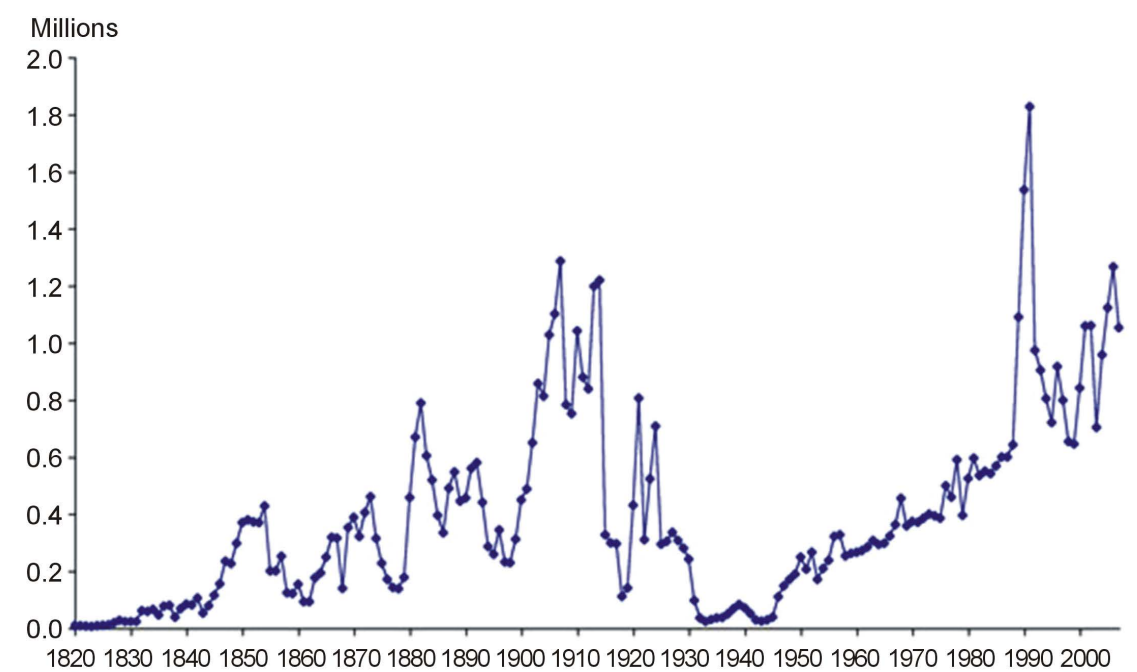

Figure 1.

Global Industrial Revolution Immigration (1880-1920) set records that stood until 2000 adopted from (National Bureau of Statistics, 2004).

and conflict in urban contexts where mixture has failed to produce social cohesion and cultural interchange. There are many neighbourhoods in which multi-ethnicity has not resulted in social breakdown, so ethic mixture itself does not offer a compelling explanation. This study explores in particular the dynamics of deprivation, segregation and changing youth cultures. The prime purpose of this study, however, is not to dwell on issues of racism and whether it exists or not, but to use the issues raised by them as a springboard to discuss what it takes to achieve a cohesion in a multi-cultural landscape, to live with difference and to encourage integration in a multicultural and multi-ethnic society. This study tries to highlight how public parks and designed landscapes create possibility for such interculturalism. It does so at the level of everyday negotiations of difference within local micro-publics (neighbourhoods) of prosaic interaction. But it also addresses structural influences and questions of public engagement, citizenship and belonging in a multi-ethnic society that all influence the capacity of individuals and groups to interact fruitfully as equals.

\section{Starting Point}

Lessons can be drawn from the United Kingdom, which has had the experience in the rejuvenation of public spaces as a key policy concern in dealing with the issues of multi-culturism in parks (Cattell, Dines, Gesler, \& Curtis, 2008). Drawing from experiences on a wide literature and on qualitative research located in a multi-ethnic area of East London, this paper also explores their relationship to well-being and social relations. It demonstrates that ordinary spaces are a significant resource for both individuals and communities. The beneficial properties of public spaces are not reducible to natural or aesthetic criteria, however. Social interaction in spaces can provide relief from daily routines, sustenance for people's sense of community, opportunities for sustaining bonding ties or building bridges, and can influence tolerance and raise people's spirits. They also possess subjective meanings that accumulate over time and can contribute to meeting diverse needs. Different users of public spaces attain a sense of well-being for different reasons: the paper calls for policy approaches in which the social and thera- peutic properties of a range of everyday spaces are more widely recognised and nurtured. Thomas (2001) rightly pointed out that it is not about people who have previously lived in or moved through today's areas of open space. But 'use' does not begin and end with physical presence: we are also interested in the extent to which people have occupied open space with their thoughts and apprehensions, desires and dreams.

\section{History of Migration, Ethic Minority in China}

In the past few decades, China has undergone enormous political, economic, and demographic changes that have transformed the realities of migration to and from the country. In addition to large flows of emigrants leaving in search of opportunities elsewhere and the persisting, more traditional streams of internal migrants for which China is known, a new trend of immigration to the fast-developing country is emerging. The driving force behind the recent trend of immigration to China the world's most populous nation has been the country's rapid economic growth, compounded by its passage through a demographic transition. The growth of the Chinese labour force is slowing drastically at a time of mounting demand for labour, and this fact has increased pressure on wages and the country's aging population. As China begins the necessary process of establishing an immigration policy to deal with its new status as a destination country (Munck, 2010). This Chinese phenomena of foreign migration and ethnicity questions, can be categorised as explained by G. William Skinner's model that brings together three ideas and types of data: the analytical concept of ethnicity; the history of internal migration in China; and the regional systems methodology, which is arguably a breakthrough in the study of Chinese society as well as an approach of broad social scientific application. Zhang (2003) writes that, the study of migration is not new in economics. The dominant approach in the 1970s was the (Todaro, 1969) model and its extension, the (Harris \& Todaro, 1970) two-sector model, which recognized the persistent wage differential between urban and rural sector. In this model an individual will make his or her migration decision based on the expected urban-rural earning difference. The prediction from the Harris-Todaro model is challenged 
by empirical evidence, and economists realized the importance of the household in the migration decision process (see Nabi, 1984; Rosenzweig \& Stark, 1989 for theories on migration and empirical results from a global perspective).

The fundamentals are also different when it has to involve bilateral, trilateral and multi-national, corporations' thirsty for profits, because corporations have always encouraged key personnel to relocate to where labour and a key component of production is favourable. This study examines the relationship between recreation in public landscapes and multi-culture social integration in the experiences and perceptions of people of various ethnic non-Chinese backgrounds based on fieldwork (observation, online survey feedback and interviews) conducted in the Chinese city of Shanghai in Puxi 浦西 and Pudong 浦 东 areas. Insights into these relations in areas were a number of foreign migrants (non-Chinese) have settled. Feedback was gained by exploring the use, experience and meaning of recreation in multi-cultural public park and landscapes and their social setting. In doing the above, it adds to existing knowledge because it speaks the language of daily life, and if daily life can be more deeply understood, we will also know the process by which it was constructed.

\section{Chinese Society: Issues of Migration, Social Integration, Recreation and the Neighborhoods}

As a result of this new trend of immigration, China is now planning to draft an immigration law that will seek to attract to China the people that it needs to support its development, Xinhua (2010). Most fundamentally, a much stronger database on the numbers, origins, and types of foreign migrants in China. Whatever the challenges, it is a major change for a country that has traditionally been concerned with emigration to begin dealing with immigration issues with which the developed world has been wrestling for some time. Official figures suggest that, overall; some 2.85 million of the 26.11 million foreigners who entered China in 2007 came for employment purposes (Xinhua, 2010; NBS, 2011). Of these, more than half a million were workers in joint ventures or wholly foreign-owned firms. Again, the majority were likely to have been skilled migrants from the developed world, including overseas Chinese from Europe, North America, and Australasia. China is also experiencing increased numbers of migrants entering the country for the purpose of study. China now ranks as a major destination for international students, with an estimated 238,184 foreign students in 2009, ahead of Australia and Canada (Xinhua, 2010).

Much is being said about immigration in China, but little is actually known about the daily realities of life for new foreign migrants or for "receiving" populations. Robinson and Reeve (2006) highlight that, even less is known about the factors shaping these realities. Much is also being made of the supposed crisis of cohesion in local neighbourhoods. Little, however, is currently known about the neighbourhood consequences of the arrival and settlement of foreign (immigrant) populations on changing community dynamics or the everyday actions, interactions, relationships and experiences of different population groups (Skeldon, 2011). This study represents an important first step towards illuminating and understanding these hidden and neglected experiences, by detailing the key insights and the principal conclusions that can be drawn from what evidence currently exists. The result, rather than an annotated review, is a discussion piece structured around a number of inferences and contentions, generated by fusing together insights drawn from these disparate sources.

\section{Perceived Theoretical Undertones}

The theoretical framework of the research is underpinned by recreation, social integration and public landscapes. Many scholars and researchers (e.g. Peters, 2011a, b; Soenen, 2006, etc.) have looked at various characteristics of public spaces and related them to different types of behaviours and interactions. Others have studied the significance of public space for leisure activities and investigated the leisure behaviour of different ethnic groups e.g. Jokovi (2000), Public Realm Rotterdam (2011) and Peleman (2003). However, not many researchers have considered the linkages between public spaces and social integration. It is only in recent years that a few researchers have tried to open this Pandora's Box. Research in the field of social integration mainly focuses on socio-economic aspects and the role of "formal leisure settings" (e.g. sport associations) in processes of socio multicultural integration Peters (2011b). Dickson, Jepsen and Barbee (2008), correctly observed that in addition to a lack of overall consideration of space, there is also a gap in literature regarding contact in leisure spaces. They further highlights that Dickson, Jepsen and Barbee (2008), since recreation and public space are related to free choice, it seems to be a fertile area in which contact research could improve our understanding of multi-culturism of ethnic relations. In recent years Ehrkamp (2005) and Roberts (2001) examined immigrants' perceptions of integration and they came to the conclusion that in order to better understand integration, immigrants' relations with particular places and their everyday encounters with and responses to dominant discourses and structures of belonging been studied.

It is the view of this research that, in Asia, little research has considered integration from the perspective of non-native residents. In this research's work, the perspective of non-native Chinese people was as important as that of native Chinese people and it is in this researcher's view that this study adds to the scientific knowledge about the meaning of multi-culture public landscapes and integration in China. This research differs from quantitative research, than to focus on the extent to which non-Chinese people in Chinese society in terms of education, housing, jobs, use of media etc, but it also tends to perceive the participation levels of native Chinese people as a the norm from which non-Chinese people should not deviate. In many sectors, participation levels are also used to show the extent to which non-Chinese people differ from native Chinese people and, in that sense, they are inevitably judgemental and reproduce stereotypes. This research also contributes to the debate on social integration in China the results add to the understanding of the role of public spaces and landscapes for the processes of social integration. It was not in the interest of this research to provide an in-depth definition of public spaces, but to provide some insight into the extent to which public spaces can play a positive role in processes of social integration, as well as highlight the challenges and short comings experienced. It is the wish of this research that, this could influence policy makers when they have to make decisions on integration policy. Peters (2011b) states that such research contributes to debates the on relationship between the quality of public spaces and quality of relations between people. 


\section{Perceived Discourse of Integration and Multiculturalism Themes from the Interviews}

As it is an interpretative research aimed at a better understanding of the phenomenon under study, it is not my intention to falsify or verify the assumptions behind the theories used in this study. Like many researchers, I used theoretical insights in order to better analyse data derived from individual experiences and perceptions. It is important to realize that the structural context in which these experiences are taking place also have to be taken into account. In order to understand the current discourse, insights into the history of migration and the development of policies around integration are needed. These migrations stern form China's immigrant population to some extent and this phenomenon is not unique to China alone, but in many "Asian Tiger economies" with recent economic growth. This has definitely had an implication with regard to neighbourhood planning and settlements in China in general.

It remains to be seen if there is any specific policy formulation aimed at the integration of foreign migrants in host societies in China. The concentration and centralization of the means of production, units of management, labour power, markets, and means of consumption form the gigantic and complex spatial unit known as metropolitan areas. These areas demand social amenities for the neighborhoods such as recreation facilities, hospitals, shopping malls, transportation networks and other services. The rise of the urban social change of conditions and all aspects of the urban praxis. It becomes necessary to make explicit assumptions on social change to be able to establish more specific links between the change of cities and the change of societies or neighborhoods. Thomas (2001) refers to international migration as being part of the process of globalization, which is reshaping economic, political and cultural systems, these numbers have doubled since 1980 . However, there is common beliefs, that the current migrant flows, which are mainly related to labour, are fundamentally different from earlier forms of mass migration.

\section{Neighborhoods Issues and Solutions}

To see oneself from the perspective of someone else can be liberating or terrifying, sometimes it is both. I hope that some sense of seeing ourselves from the perspective of others informs the following discussion concerning an inquiry into ethnicity and landscape (Thomas, 2001). While the connection between cultural background and landscape experience is the theme that unites this project, the consultative methodology that produced it broke down the demarcation between researcher and research subject, which is often rigid. It proved impossible to dissociate people's experiences in parks from their insights on the Landscape and Parks. As shown in Figure 2 Shanghai has seen a surge of foreign immigrants in recent years. In this respect the research into ethnicity and landscapes or parks presented here provides a mirror for an invaluable opportunity to consider how effectively landscapes and parks are meeting the needs of a very large minority of the population in Shanghai, China.

\section{Perceived Socio-Economic Trends of Shanghai}

Shanghai is China's largest city, one of the three centrally-administered cities that stand at the top of the pyramidal hierarchy that defines the structure of rural-urban relations in

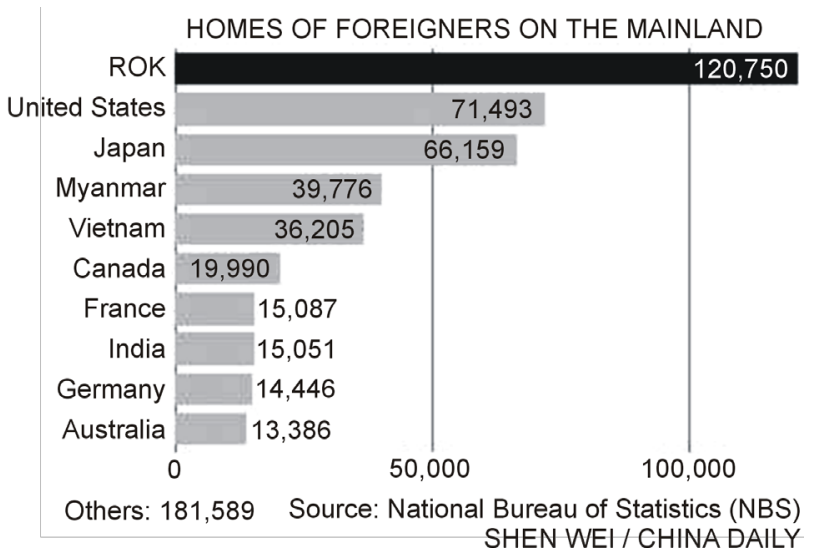

Figure 2.

Foreigners on Mainland China, Source; The sixth national census released by the National Bureau of Statistics (2011).

China [28]. It is worth noting that migration is blind Roberts (2001), who traces the foreign migrant flows as a result of multinational logit regression of sector of employment on migrants' characteristics. The selected subject areas of study are basically areas of Shanghai were many foreign multinational companies have set base themselves and where employees have made their homes. Many of these non-Chinese have overcome their language disadvantages with foreign schools thriving and pupils are successful in their primary school and a number taking up Mandarin classes. The experiences in Pudong and Puxi areas of Shanghai by many foreign park users were varied widely and are very much an ideal of "multicultural cohesion". An online survey (conducted through surveymonkey.com) brought out many notable cultural clashes in respondents' day-to-day use of public parks, based on their individual perceptual experiences, views and opinions. Many respondents felt and described the local public park users as self centred with very little regard to other park users.

Some foreign park users took offence at always been called “foreigner” 老外 by locals communities saying look at that foreigner or being pointed at, being curiously stared at and looked at with suspicion. These are some of the many areas that many foreign-migrant respondents found hard and difficulty to cope with and enjoy their day out in the public parks. Further, some respondents felt that this defeats the whole purpose of wanting to go to a public park for the quiet and relaxing experience. Which they so eagerly want to get away from their busy schedules of work and school. The use of park walkways as skating areas defeats the purpose of retreating to a quite park. Many respondents further pointed out that the essence of a bio-diversity and well-cared for parks, however, this ideal get challenged when locals allowing their children to urinate on the grass and by people littering. Some were quick to state that, such problems are not unique to China alone, but are universal public problems that require the constant sensitisation of the local' neighbourhoods on public etiquettes and public health by the local authorities responsible.

\section{Perceived Minority Policy in China (Fallacy or Reality)}

Policies on minorities are centred on the terms "integration" and "multicultural society” Hollands (2006). These policies are 
targeted at the full participation of minorities in their new societies; the minorities should adjust themselves to the dominant norms and values of their new society. Integration policies can be divided into three groups: assimilation policies, integration policies and multicultural policies. Assimilation policy aims at full adjustment to the culture of the majority, while integration leaves some room for the conservation of individual identities and culture (Essed, Frerks, \& Schrijvers, 2005). Multicultural policies emphasize the acknowledgement of diversity: societies must change in order to accommodate all ethnic and cultural groups that form part of that society (Essed, Frerks, \& Schrijvers, 2005; Parekh, 2000; Taylor, 1995). It remains to be seen if there will ever be a Chinese policy of integration. Many people have asked this question looking at the global demographic situation that reflects the acceptance of many Chinese who have resettled outside- of China Parekh (2000). In that sense, many expect and acknowledge that people from various ethnic and cultural backgrounds live together in many parts of the world now Peleman (2003).

A well-articulated policy towards foreign immigrants is suggested as a welcome phenomenon, in places like China were a foreigner remains a foreigner in the eyes of many native Chinese. The Dutch government in 1980, proposed and implemented tailor-made measures for specific foreign migrants groups (Poppelaars \& Scholten, 2008). These were "two-track" policies: they were aimed at integration in the Dutch socioeconomic sphere while retaining the cultural identities and group structures in order to facilitate the eventual return (Poppelaars \& Scholten, 2008). The above case may be true for the Dutch, the Chinese could also start with a plea from the a scientific Council for Government Policy for recognition of the fact that several foreign immigrant groups have effectively settled permanently in China and most likely will not return to their countries of origin. The fact that migrant groups also share certain ethnic attributes offers an opportunity for policies to be drawn along those lines and the need to establish a dialogue with representatives of ethnic foreign minorities.

\section{Perceived Emerging Differences from Ethnic Diversity}

Peters (2011) highlights the model of cultural dimensions that can be used as a framework to understand how cultural background influences behaviour. The survey found that, foreign nationals have somehow created their own areas of outdoor interaction and specific parks that are somehow detached from interaction with the locals. This begs the question, could public parks as vehicles of multicultural interaction be said to have failed in facilitating interaction between ethnic groupings and multicultural neighbourhoods.

However, it is important to be careful not to reproduce stereotypes by using an essentialist definition of culture or religion Taylor (2002). The conducted interviews, though limited to a few foreign migrant experts and native Chinese residents around Shanghai. There were very sceptical responses, but were able to give an insight into the general situation in Puxi and Pudong. The experts provided rough information about the use of the public spaces, and specific characteristics of the neighbourhoods and groups of people. As shown above, not all interviews were recorded and transcribed for data analysis. Many people were not comfortable to be interviewed and recorded without prior clearance from authorities.
Nevertheless, note taking proved useful in summarizing the participants' responses and records. This was complemented with observation of the public spaces between April, 2011, and August, 2012. As Spradley (1980) observed, special interest was taken in the physical setting, the available facilities and housing stock, which together form the habits of everyday use of public space. Public spaces and parks were visited on various days of the week, in an effort to get a feel of the surroundings and to trace everyday interactions, events, social situations, actions and encounters. Special attention was paid to the presence of inter-ethnic interactions. This was meant not to determine the ethnic identity of individuals, but to get an idea about who is present in various public spaces and what they were doing.

\section{Analysis}

Avoid In analysis, the above was not a linear process and cannot be fully transparent. It should be noted that this analysis was guided by theoretical sensitivity and an iterative process that involved continual interplay between the data and the background literature Strauss and Corbin (1998). The analysis was not guided by prior hypothesis, so the themes emerged from data. The analytical process involved carefully rereading the data to discover common themes and to differentiate the accounts provided by participants in order to acquire an understanding and knowledge of phenomena from the point of view of those who were under study. It is worth noting that, this study does not offer generalisations, but describes the meaning of multicultural integrations in public spaces and landscapes.

Strauss and Corbin (1998) draws that in positivistic research, reliability and validity are used in order to discuss the replicability and accuracy of the findings in a specific way, and qualitative research this is less clearly defined. For validity, qualitative researchers use different strategies and terms. Sandelowski (1993) argued that validity in qualitative studies should be linked not to "truth or value", as they are for the positivists, but to "trustworthiness", which "becomes a matter of persuasion whereby the scientists is viewed as having made those practices visible and, therefore, auditable” (Sarantakos, 1993).

\section{Lessons and Conclusion}

Many foreign immigrant populations are characterised by a distinctive regional geography and in Jinqiao 金桥, Pudong and Yangpu 杨浦 Puxi, residents by and large are satisfied with the contacts they have around Shanghai. The idea of this study was to address the research gap by focusing on everyday life in foreigners' multicultural-ethnic neighbourhoods of Shanghai, and on how native Chinese and non-native people live. This was to gain an evaluation of experiences in public spaces and landscapes contribute to "feeling" at home in a multicultural Shanghai neighbourhood. These contacts are mainly non-intimate and supporting ties between the non-Chinese and native Chinese that enable these residents to live their everyday lives in Jinqiao and Yangpu of Shanghai more easily and more joyfully. Residents mainly have developed some contact with people from the same ethnic groups or backgrounds, although also inter-ethnic relations are formed. It appears that confrontations with diversity in public spaces and landscapes did not often lead to inter-ethnic private bonding. In public life multicultural and ethnic diversity is visible in various places, and these short encounters have often lead to more enduring friend- 
ships among the communities. It was an objective to gain insight into the meaning of urban public spaces and landscapes for social multicultural integration.

\section{Future Prospects of Multicultural Landscapes}

It is worth learning that, being an immigrant does not make one less human, but it is a challenge to new urban planners and policy makers alike to sort out these challenges by designing ever-growing multicultural communities. The positive experiences about diversity have a significant impact on peoples' attitudes, and also links to the way in which residents talk about integration and multiculturalism. Integration is a commitment to and participation in the place where they live; integration relates to issues of belonging and participation, rather than to adaptation or assimilation. The above perspective is derived from the basis of the everyday lives of residents who are committed to and actively involved in their neighborhoods. This study highlighted gaps in current understanding and presented possible priorities for future research.

\section{Acknowledgements}

The authors wish to express their gratitude to many people who wish to remain anonymous for the assistance in making suggestions, corrections and to the would be referees for their valuable and helpful comments, which have improved the quality of the paper. Also, extend our thanks to The Copperbelt \& Tongji University especially the Department Landscape studies.

\section{REFERENCES}

Amin, A. (2002). Ethnicity and the multicultural city: Living with diversity. Environment and Planning A, 34, 959-980.

http://dx.doi.org/10.1068/a3537

Cattell, V., Dines, N., Gesler, W., \& Curtis, S. (2008). Mingling, observing, and lingering: Everyday public spaces and their implications for well-being and social relations. Original Research Article Health \& Place, $14,544-561$.

Dickson, G. L., Jepsen, D. A., \& Barbee, P. W. (2008). Exploring the relationships among multicultural training experiences and attitudes toward diversity among counseling students. Journal of Multicultural Counseling and Development, 36, 113-126. http://dx.doi.org/10.1002/j.2161-1912.2008.tb00075.x

Ehrkamp, P. (2005). Placing Identities: Transnational practices and local attachments of Turkish immigrants in Germany. Journal of Ethnic and Migration Studies, 31, 345-364. http://dx.doi.org/10.1080/1369183042000339963

Essed, P., Frerks, G., \& Schrijvers, J. (2005). Refugees and the transformation of societies agency, policies, ethics and politics. Berlin: Springer.

Harris, J. R., \& Todaro, M. P. (1970). Migration, unemployment and development: A two-sector analysis. American Economic Review, 60, 126-142.

Hollands, M. (2006). Rappin' on the reservation: Canadian Mohawk youths hybrid cultural identities. Sociological Research, Online, 9. www.socresonline.org.uk/9/3hollands.html

Jokovi, M. (2000). Recreation Turks, Moroccans and Surinamese in Rotterdam and Amsterdam, an exploration of leisure behavior and the effects of the ethnic culture of leisure. Wageningen: Alterra Research Institute for the Green Space.

Macpherson, W. (1999). The Stephen Lawrence inquiry. London: Stationery Office.

Merrifield, A., \& Swyngedouw, E. (1996). The urbanization of injustice. Oxford: The University of Oxford, NYU Press.

Munck, R. (2010). Globalisation, migration and work: Issues and pers- pectives. Labour, Capital \& Society, 43, 155.

Nabi, I. (1984). Village-end considerations in rural-urban migration. Journal of Development Economics, 14, 129-145. http://dx.doi.org/10.1016/0304-3878(84)90046-4

Nagel, C. (2002). Constructing difference and sameness: The politics of assimilation in London's Arab communities. Ethnic and Racial Studies, 25, 257-287. http://dx.doi.org/10.1080/01419870120109485

National Bureau of Statistics (2004). Women and men in China Facts and figures. Beijing: Department of Population, Social, Science and Technology, National Bureau of Statistics.

National Bureau of Statistics of People's Republic of China National [NBS] (2011). Highlights of China's sixth national census results. http://www.stats.gov.cn/english/

Novica, A. (2001). The multicultural landscape: National parks and the Macedonian experience. NSW NPWS, 82.

Parekh, B. C. (2000). Rethinking multiculturalism: Cultural diversity and political theory. GB: MacMillan, Istanbul: Phoenix.

Peleman, K. (2003). Power and territoriality: A study of Moroccan women in Antwerp. Tijdschrift voor Economische en Sociale Geografie, 94, 151-163. http://dx.doi.org/10.1111/1467-9663.00246

Peters, K. (2011a). Living together in multi-ethnic neighbourhoods: The meaning of public spaces. Wageningen: Wageningen Academic Publishers.

Peters, K., \& De Haan H. (2011b). Everyday spaces of inter-ethnic interaction: the meaning of urban public spaces in the Netherlands. Leisure/Loisir (Special Issue: Leisure, Space and Social Change), 35, 196-190. http://dx.doi.org/10.1080/14927713.2011.567065

Poppelaars, C., \& Scholten, P. (2008). Two worlds apart. The divergence of national and local immigrant integration policies in the Netherlands. Administration \& Society, 40, 335-357. http://dx.doi.org/10.1177/0095399708317172

Public Realm | Rotterdam Lijnbaan TU Delft | Faculty of Architecture |MSC 3 Studio (2011). Multi-cultural public life, "how does the multi-cultural life of Rotterdam translate in the contemporary public realm of the city?” Netherlands.

Roberts, K. D. (2001). The determinants of job choice by rural labour migrants in Shanghai. China Economic Review, 12, 20-23.

Robinson, D., \& Reeve, K. (2006). Neighbourhood experiences of new immigration: Reflections from the evidence base. York: Joseph Rowntree Foundation.

Rosenzweig, M. R., \& Stark, O. (1989). Consumption smoothing, migration, and marriage: Evidence from Rural India. Journal of Political Economy, 97, 905-926.

Sandelowski, M. (1993). Rigor or rigor mortis: The problem of rigor in qualitative research revisited. Advances in Nursing Science, 16. http://dx.doi.org/10.1097/00012272-199312000-00002

Sarantakos, S. (1993). Social research. Basingstoke: Macmillan.

Skeldon, R. (2011). China: An emerging destination for economic migration. Migration Information Source: Country Profiles

Soenen, R. (2006). Het kleine ontmoeten: Over het sociale karakter van de stad (Little encounters: About the social character of the city). Antwerpen: Garant Uitgevers n.v.

Spradley, J. P. (1980). Participant observation. Orlando, FL: Harcourt Brace Jovanovich College Publishers.

Strauss, A., \& Corbin, J. (1998). Basics of qualitative research; Techniques and procedures for developing grounded theory (2nd ed.). Thousand Oaks, CA: Sage.

Taylor, M. C. (1995). White backlash to workplace affirmative action: Peril or myth? Social Forces, 73, 1385-1414.

Taylor, M. C. (2002). Fraternal deprivation, collective threat, and racial resentment: Perspectives on white racism. In I. Walker, \& H. Smith, Eds., Relative deprivation: Specification, development, and integration (pp. 13-43). Cambridge: Cambridge University Press.

The Parekh Report (Runnymede Trust, 2000). The future of multiethnic Britain: Challenges, changes and opportunities (pp. 23-24). Reading: University of Reading.

Thomas, M. (2001). A multicultural landscape: National parks and the Macedonian experience. Sydney: The NSW National Parks and Wildlife Service and Pluto Press.

Todaro, M. P. (1969). A model of labor migration and urban unem- 
LIU B. Y., F. M. MWANZA

ployment in less developed countries. The American Economic Review, 59, 138-148. http://www.jstor.org/stable/1811100

Xinhua (2010). China plans draft immigration law. China Daily. Available online, Viewed: 15/08/2012.
Zhang, F. (2003). Recent situation of economic development and migration employment in China. In Migration and the labour market in Asia: Recent trends and policies (pp. 185-191). Paris: OECD. 